DOI: 10.2478/ausfm-2019-0006

\title{
Shadows Illuminated. Understanding German Expressionist Cinema through the Lens of Contemporary Filmmaking Practices
}

\author{
Gerald Saul \\ University of Regina (Canada) \\ E-mail: Gerald.Saul@uregina.ca \\ Chrystene Ells \\ Director, Moxie Films, Regina (Canada) \\ E-mail: chrystene.ells@gmail.com
}

\begin{abstract}
The article looks at German Expressionist cinema through the eyes of contemporary, non-commercial filmmakers, to attempt to discover what aspects of this 1920s approach may guide filmmakers today. By drawing parallels between the outsider nature of Weimar artist-driven approaches to collaborative filmmaking and twenty-first-century non-mainstream independent filmmaking outside of major motion picture producing centres, the writers have attempted to find ways to strengthen their own filmmaking practices as well as to investigate methods of re-invigorating other independent or national cinemas. Putting their academic observations of the thematic, technical, and aesthetic aspects of Expressionist cinema into practice, Ells and Saul illustrate and discuss the uses, strengths, and pitfalls, within the realm of low-budget art cinema today.
\end{abstract}

Keywords: Expressionism, cinema, filmmaking, authenticity, interdisciplinarity.

In this paper, Gerald Saul and Chrystene Ells discuss - on the basis of their creative experience - how analytical knowledge of German Expressionist film movement and its aesthetic and conceptual tropes, as well as production practices, can inspire contemporary independent filmmakers. German Expressionism has deeply influenced the visual language of cinema, and though many of the methods of subjective storytelling, pioneered by the Expressionists have been incorporated by contemporary storytellers, the etymology of these cinematic tropes is still not widely understood. With the increased access to newly discovered and restored historical works, however, the vault of Expressionist films has opened to a new generation of scholars, filmmakers and audiences. 
The Caligari Project - a multidisciplinary arts festival, held in Regina, Canada reconfirmed the unwavering fascination with German Expressionism. Organized by local artists and academics, and held over a twelve-month period in 2016, the Caligari Project was a celebration of Expressionist pioneers in cinema, visual arts, music and theatre, and facilitated the in-depth exploration of Expressionist film techniques as well as their historic context. For the filmmakers involved in the project, the festival presented a welcome opportunity to enrich their production experience thanks to a post-modern return to narrative and formal techniques of cinematic Expressionism - approaches to acting, cinematography, and editing but also to its production and budgeting methods.

As filmmakers with first-hand experience in resuscitating these almost century-old cinematic techniques in the films they made for the Caligari Project, Ells and Saul relate below their hands-on experience with German Expressionist cinematic and conceptual approaches, and the invigorating influence of these. The first part of the chapter therefore scrutinizes production methods, visual style, recurring themes and narrative structures of the historical movement, and the second looks at how these were integrated within their own works.

As is well-known, German cinematic Expressionism - while part of an international multi-disciplinary aesthetic movement, which emerged in Central Europe in the early 1900s - was actually born in the early years of Weimar Germany and ended with the rise of the Nazis. ${ }^{1}$ The social forces that influenced German Expressionist cinema were both artistic and financial, facilitated by the growing collaboration of filmmakers after World War One. Although rooted in early artistic experiments with abstraction and the work of the Symbolists, cinematic Expressionism manifested a distinct reaction to the culture shock of WWI, which wrenched western culture away from its 19th-century values. While film production in pre-war Germany was strictly hierarchical, the post-WWI economic and political circumstances called for free collaboration of artists from film, cabaret, visual art, dance, theatre, music, and literature. This situation existed for a short period of time, yet it stimulated an outburst of innovative energy.

The last vestiges of German cinematic Expressionism were wiped out by the establishment of the so called socially positive art, forcefully supported by the Nazi government circa 1937. This compelled Expressionist filmmakers to either

1 While sources agree that the first German Expressionist film, The Cabinet of Dr. Caligari (1920) marked the beginning of German cinematic Expressionism, there is discrepancy as to its finale, with some authors claiming that it came with the premiere of Fritz Lang's Metropolis in 1927, whose enormous budget almost sank UFA and forced Erich Pommer to quit as its leading producer. Others shift the final date in 1931, when $M$ - another of Lang's classics - was released. 
change their artistic style; leave Germany or face extreme repercussions. By the mid-1930s most members of the Expressionist film community had relocated - first to France and then to Hollywood, which claimed such iconic figures as film producer Erich Pommer, who was instrumental in launching and sustaining the movement; directors Fritz Lang, F. W. Murnau, Wilhelm Thiele, as well as a number of camera, staging, and lighting experts.

Film has always been a complex and generally expensive medium. The problems with daunting technical costs, funding sources, and marketing, all stretch back to the first days of cinema. In the early 20th century, American filmmakers left New York to avoid the tangle of financial and legal constraints of the raging patent battles, enforced by the Edison Corporation (Bach 1999, 30). Moreover, in their search for reduced costs of filming, they settled on the US West coast, where the sunny climate advanced cost-effective open-air shooting. As Hollywood became an established film centre, so did the Hollywood production aesthetics: continuity editing, naturalism, and most importantly, the signature happy ending (Tsivian 2004, 342). Yet before the beginning of WWI, silent films from various countries - thanks to their adaptability to different language markets - continued to find wide audiences internationally. However, the war, and especially the postwar devastation, dealt the European and British cinemas a hard blow, severely limiting their ability to hold on to their national markets, let alone compete internationally. It did not take long to recognize the existential threat the growing Hollywood empire represented to national cinemas worldwide. Yet the threat of "Americanism (or naturalism) that has been so violently forced upon us" was recognized as the much bigger threat to the future of film as art (Reimann 2016, 439-440). Luckily, by that time the former belligerent countries had already acknowledged the mobilization power of film, and once the peace treaties were signed, they quickly passed protectionist laws meant to preserve and promote their national cinemas, which generated wide support for preservation of film as part of national cultures.

The situation in Germany was more complex. According to Thomas Elsaesser, a strong film community had been formed around the Universum Film AG (UFA) studio, "the only film company ever to think it could compete with Hollywood" $(2016,3)$. There were also smaller film production studios that have sprang up during the war, which - thanks to the wartime distribution quotas, imposed on foreign films - were also coping. Yet lifting of the embargo on foreign films - along with the crippling financial obligations and retributions, imposed on post-war Germany - almost dried up the market for anything German outside Germany, 
and thus accounted for a completely different filmmaking situation in 1919 (Brockmann 2010, 13). With German currency devalued, German filmmakers were also denied the possibility to make films abroad, which forced them to explore alternative methods, restricted to local studio shooting.

\section{Expressionism as a Style}

In her biography of German film producer Erich Pommer, Ursula Hardt describes the struggling of the German film community to find a method of turning these constraints into assets. Several prominent filmmakers - Robert Wiene, Fritz Lang, G. W. Pabst, F. W. Murnau, Arthur Robison, Paul Leni, and Paul Wegener - were tasked by Pommer and other producers to devise works that would uphold a look and feel that is fundamentally different from that of the romantic and realistic foreign films, made in Hollywood, France, Italy, and Denmark (Hardt 1996, 48). The revolutionary-like solution could be formulated along the lines of "if you can't beat them - change the rules." Pressure to use new tools prompted these filmmakers to explore a different side of cinema, which is eloquently described by director Robert Wiene: "naturalism," he wrote in 1922, acknowledges that "diffused light is real and studio lighting is a lie" $(2016,436)$. Yet, he goes on to say, "expressionist artists discovered [that] there is another, second reality of the photographic plate, different from that of the human eye," and concluded that "expressionism [...] places the soul above nature" (2016, 436).

By incorporating uniquely dark and complicated stories, fantastical settings and set designs, unnatural and metaphorical shadows, lighting and stylized acting, the Expressionists created a set of stylistic hallmarks that allowed them to advertise their films as unique, which proved to be an effective marketing strategy. Therefore, The Cabinet of Dr. Caligari (Das Cabinet des Dr. Caligari, Robert Wiene, 1920), The Golem (Der Golem, wie er in die Welt kam, Paul Wegener, 1920), Destiny (Der müde Tod, Fritz Lang, 1921), Nosferatu (Nosferatu, eine Symphonie des Grauens, F. W. Murnau, 1922) and Warning Shadows (Schatten - Eine nächtliche Halluzination, Arthur Robison, 1923) were not only distinct from anything seen on film before, but also critically and internationally successful. Even after budgets stabilized and distributions prospects improved during the post-war years, German films continued to utilize the established Expressionist conventions, although often moving away from their basic tenets.

To be sure, most significant artistic movements have been theorized post factum, and even then, with mixed results. In the words of the famous French New Wave 
historian Michael Marie, what the "fragile notion of [German] Expressionism demonstrates" could easily be challenged if the list of its alleged common traits is applied to more than two films from the historic movement (Marie 2003, 28). Yet Expressionism, he rightfully claims, "continues to return through the windows of critical discourse" $(2003,28)$. Therefore not all films made in Germany at that time and even by the above-mentioned directors, were strictly speaking Expressionist in the manner displayed by Caligari or Nosferatu. Nonetheless, the undisputed pre-eminence of style brings German cinematic Expressionism into the fold of European avant-garde Expressionist movement in visual arts, theatre, music, and literature, and precludes attempts to define it as a specific film genre.

As an organically evolving cinematic style, Expressionism has naturally opened up to borrowings and redefinitions for generations to come. Director Josef von Sternberg, for example, while using a more naturalistic style in his German film The Blue Angel (Der blaue Engel, 1930), allows for a particularly strong Expressionist influence to shape the garish backgrounds of the underworld Cabaret of Marlene Dietrich's Lola Lola, and paints the tragic downfall of Emil Janning's Prof. Immanuel Rath. Similarly, Fritz Lang's meticulously stylized sound film $M$ ( $M$ - Eine Stadt sucht einen Mörder, 1931) represents a bridge between his Expressionist German films and his later film noir work in America. $M$ is set in an abstract world, where danger lurks around every corner and social norms are reversed, with paupers and thieves taking on the roles of judges and juries, and where the narrative point of view flips from objective to subjective, effectively pulling the audience into the tortured world of Peter Lorre's unhinged child molester.

\section{Low Budget Cinema and Expressionism}

After emigrating to America, Austrian-born cameraman and lighting expert John Alton published Painting with Light in 1949. His book was the first one to be written by a major cinematographer on cinematography, and to lay the ground work for the metaphorical use of studio light. Alton's influence on Hollywood, more specifically the continuity he secured between German Expressionism and American film noir (Schrader qtd. in Bergstrom 2014, 38), reveals that connection to be not so much theoretical but practical, a result of expertise, migrating from one country to another. Foster Hirsch explains: "these early Expressionist films, with their tormented protagonists in flight from an alien society, and their stylized urban settings, exerted a deep influence on the subject matter as well as the visual temper of the American film noir. Expressionist motifs filtered into film noir, in 
diluted but nonetheless significant ways, because the German style offered an appropriate iconography for the dark vision of the forties thriller, and also because a number of German directors fled to Hollywood from a nightmare society, bringing with them the special sensibility that permeated their early work" $(1981,57)$.

While funding is rarely proportional to the quality of art - as Orson Welles once observed, "the enemy of art is the absence of limitations" - it does affect the choices of the film producer (qtd. in Jaglom 1992, 74-78). In highly commercialized film production centres (most notably Hollywood), large crews work under top-down management, efficiently carrying out the intense labour of making films. Creative decisions are made by producers and directors, without collaborative discussions or consultations with the production crew. Each crew person, on the other hand, contributes to the creative whole according to management specifications, in a manner similar to an assembly line, where efficiency is prioritized over innovation.

Conversely, the loss of human and financial capital had a major impact on post-war film production in Germany, derailing established hierarchies and curtailing the use of large crews of specialized technicians. Left without funding or infrastructure, and almost no access to world markets, the members of the relatively small community of German filmmakers were forced to wear multiple hats in their respective film productions and solicit help from friendly artists and designers. By working in teams that were small, less hierarchical, and diversely skilled, filmmakers could collaborate better and easier, thus getting used to taking on jobs above or below their status or standard crew position. Such fluidity of responsibilities saw set designers influencing narrative decisions, and directors getting involved with more technical aspects of the production, which resulted in what was basically an ideal situation for creative innovation (Elsaesser 2016, 29). The stylistic hallmarks of early Expressionist films like Caligari, reflect the expertise of painters, carpenters and costume designers, recruited from theatre, visual art, and underground cabarets. Fritz Lang thus became an excellent expert in cameras, optics, and mechanical contraptions, whose crown achievements were Metropolis (1927) and Die Nibelungen (1924), his most complex works.

A closer look at the production of Caligari reveals an unmistakable interrelatedness between funding and aesthetics. Shot in 1919 and released in 1920 , its cost was a meagre $\$ 18,000$, less than half the cost of a regular low budget feature made in Hollywood at the same time. In Caligari, the camera and lighting are secondary to set construction, design, costumes, makeup, and performance. While the camera does little more than record a theatrical presentation since the 
film's famously flamboyant shadows are in fact painted on props and backdrops in a bold and striking manner, described eloquently by Lotte Eisner: "cubical houses falling obliquely forward, with crooked and irregular windows and shapeless doors that look like ravenous jaws, facing on narrow streets dark as night that zigzag into nowhere" (1980, ii).

She sees the role of set designers in Caligari as instrumental in shaping the Expressionist aesthetics since - once written - "the script was immediately handed over to them" (Eisner 1980, ii). She goes on to quote the "strong adherent of Expressionism, Walter Reimann," who declared that "the sets should not be three-dimensional plaster creations but built up by a series of large painted canvases" (Eisner 1980, ii).

Yet just seven years after Caligari, the production costs of Metropolis went over one million dollars, and allegedly put an end to German Expressionism by pushing into bankruptcy Erich Pommer, its powerful and creative producer. Nonetheless, Expressionist aesthetic devices - subjective point of view, extreme compositional angles, forced camera perspectives and optical illusions, emphatic shadows and unnatural sets - went on to mark the visual style of Weimar cinema throughout the early 1930s. This spirit of experimentation is best demonstrated by Murnau's The Last Laugh (Der letzte Mann, 1924), where the cinematographer used a miniature (by 1920's standards) camera, transported on a clothesline, to create a shot that captures the unrelenting spread of gossip that haunts the main character. Although Expressionist narratives are difficult to comprehend by contemporary audiences, the films themselves remain watchable because of their vital cinematic language. The subjective lighting and extreme graphic composition, used to convey psychological tension in Lang's M, Dr. Mabuse, the Gambler (Dr. Mabuse, der Spieler, 1922) and in Arthur Robison's Warning Shadows (1923), have remained stunning to this day. The propensity of their visual devices to enthral the viewer, but to also reveal with self-reflexive zest their craftsmanship, has helped make the evocative German Expressionist style truly attractive for low budget filmmakers.

\section{Expressionism and the Externalization of Mental States}

Another major contribution, made under the growing influence of Sigmund Freud and Carl Gustav Jung in the 1920s, was the pioneering interest of German Expressionists in deep psychological recesses, hitherto uncharted by cinema. It is important therefore to note how much the look of these films contrasts with the classical look of mainstream cinema at the time, whose naturalism could be 
compared to the Renaissance art, with its open framing considered a window onto the outside world. The Expressionist screen, on the other hand, comes through as a portal onto an inside world, through which - as in Caligari - the audience is transported into the nightmarish space of the twisted inner world of the narrator. In it, like in contemporary films strongly influenced by the Expressionist masterpiece like Shutter Island (Martin Scorsese, 2010) or Fight Club (David Fincher, 1999), the delusion is shared by both the audience and the narrator. In another Expressionist classic, Warning Shadows, a magician at a dinner party flipsides the waking consciousness of the guests with its unconscious shadows, making them reveal their darkest secrets and lustful desires. The viewers are not just observers of this shocking reversal but - because of the effectively inventive camera positions - feel themselves as participants in the ensuing carnal drama. The construction of this uniquely nightmarish world, where no one - viewers included - is innocent, has certainly inspired many an imitation with various degrees of originality and effectiveness as it allows the director to not only tell a story, but to also create the uncanny realm that story evolves.

The impact of Expressionist fascination with the murky recesses of human psyche - and the distinctive way they were epitomised on screen - continues to be strongly felt to the present day. It is enough to mention American director Tim Burton, whose films are consciously intertextual with regard to both images and themes, borrowed from German Expressionism. In his Edward Scissorhands (1990), for example, the eponymous protagonist is not only a visual replica of Cesare the Somnambulist from Caligari, but the story itself is full of references to man-made creatures gone wrong, familiar from early silent films like The Golem (1915) and Frankenstein (J. Searle Dawley, 1910). Even filmmakers, whose work tends to be more naturalistic than Burton's, also demonstrate affinity for Expressionist narrative and stylistic devices. In the Lord of the Rings trilogy (Peter Jackson, 2001-2003), for example, Peter Jackson portrays the Evil from the Mordor realm with unmistakable Expressionist touch. The imbalanced framing, oblique architecture, sharp angles in costuming, landscapes and shadows, and high contrast lighting - which reduce the desaturated palette of Mordor to almost pure black and white - are all elements drawn from Nosferatu and Caligari, considered to be among the earliest cinematic examples of horror cinema. Furthermore, Jackson's design displays unmistakable Expressionist influence in the striking juxtaposition of Mordor and the Dwarfish realms to the heroic Elven one. With its low lighting contrasts, rich colour palette, and overall design of majestically towering silhouettes, symbolizing nature and purity, the Elven 
realm is heavily influenced by Art Nouveau and Art Deco, thus bringing to mind the striking contrasts in Lang's Metropolis between the upper, civilized, genteel world of Art Deco fountains and exotic birds, and the lower, shadowy world of the workers, immersed in death, fear, and suffering.

\section{German Expressionism, Experimental Cinema, and the Caligari Project Films}

It should be clear by now as to why contemporary independent filmmakers frequently draw on German Expressionism in terms of style, themes, and production methods. Since the main challenge for indie production is sustainability, small collaborative teams are standard, especially in lower or nobudget films, where creative challenges are prioritized over higher wages, and conducive of work environment with a blended hierarchy of jobs and duties. It is therefore not uncommon for an indie film to have a professional gaffer working as a camera operator; a writer doing production design, or a sound recordist performing as an actor. As the careers of such diverse filmmakers like David Lynch, Jim Jarmusch, Guy Maddin, and Jane Campion demonstrate, it is through such passion projects that new directions in the art of cinema emerge. It is also true that while an independent filmmaker's first, often no-budget film, is swept through production, distribution, and exhibition on the buoyancy of cast and crew, their next film is usually fraught with funding issues. Cast and crew might do whatever it takes to get an occasional low or alternatively funded dream project off the ground, but they cannot make every film a labour of love. People need money in order to live, and their commitment to the production is inevitably measured against remuneration. This naturally constrains improvisation and experimentation during the shooting stage as time becomes a significant restricting factor, which cash-strapped filmmakers are unable to circumvent. This pattern leads to ghettoization of filmmakers, who work on low budget and independent productions, and - as is often the case - to being looked down upon as amateurs or hobbyists by their mainstream industry counterparts. To make matters worse, low budget and independent films could rarely find distribution outside the film festival circuit. Yet work on a smaller scale, despite the perennial funding challenges, could be a unique professional experience for all those involved on and off set, including funders and producers.

Needless to say, the sustainability of the low-budget to no-budget filmmaking model is particularly indispensable for filmmaking communities in smaller cities, 
regional centres, and certainly for cinematic counter-culture movements in large centres. Therefore, one of the goals of the Caligari Project was to revisit the historical Expressionist production model and test its strengths against a new generation of independent filmmakers. During 2016, three short films were made by two of the principal organizers of this interdisciplinary cultural event. Chrystene Ells (in collaboration with Berny Hi) made Der Glöckner (2016), and Gerald Saul made Eyes of Sorrow Moon and The Testament of Frankenstitch (2016). Each of these works took a new approach to German Expressionism, furthering explorations of its aspects, which have already influenced both Ells's and Saul's earlier works - from mysterious stories, rooted in arcane psychological worlds, to stylized lighting, design and performance, to the inventive use of low budgets. Therefore each of their films, as it were, was designed as a post-modern intertextual pastiche, paying homage to the cinematic movement, being at the same time closely aware of the pitfalls of any superficial imitation of its formal aspects.

\section{Der Glöckner}

The collaborative team Chrystene Ells (director) and Berny Hi (cinematographer) designed Der Glöckner (German for bell-ringer) as an authentic Weimar film. On the basis of in-depth research, they chose a three-fold approach: in technical terms, they adapted to the contemporary reality of their shoot as many practices of the German collaborative production team model as possible; thematically, they chose from a wide range of Expressionist tropes, archetypes, and psychological discourses; visually, they remained true to Expressionist design and performance, emulating images, staging patterns, and scenes. Ultimately, Ells and Hi aimed at a universally knowable film, which would replicate the silent-era cinematic offerings by relying mostly on the visuals and physical performance, restricting to minimum the usage of contemporary technology. Thus spoken words and intertitles were eschewed as in Murnau's The Last Laugh, while the project was shot on celluloid, ${ }^{2}$ and all visual effects were created in-camera. Iris-out transitions and the fading out of a translucent ghost-like character were created physically through camera manipulation, rather than using current CGI practices.

In the spirit of most German Expressionist films, Ells and Hi staged and shot all scenes but one in studio, thus securing maximum control over the visual storytelling. As Eisner writes, in-studio shooting became a prevalent practice

2 For budgetary reasons the smaller $16 \mathrm{~mm}$ gauge was used rather than the historically accurate $35 \mathrm{~mm}$. 
of German Expressionism under the dominant influence of contemporaneous theatre, helmed by Max Reinhardt, also known as the "magician of light" (1980, i). ${ }^{3}$ Through their dramatic visualizations, Expressionist directors were aiming at creating that elusive Stimmung - an untranslatable German word, used to describe the mood or atmosphere, created by stylized performances, otherworldly environments and chiaroscuro effects (1980, i).

The budget for Der Glöckner was $\$ 10000^{4}$ - inordinately small if one is to calculate the actual expenditures against conventional production planning, which would bring the cost to an estimated $\$ 150000 .{ }^{5}$ Modelling the production after the historic approach to Expressionist cinema was therefore driven by both aesthetic and finances. Local visual artists and theatre designers generously agreed to build the sets, while artists, friends, a handful of actors, and emerging filmmakers staffed most of the cast and crew. Costumes were borrowed from a local theatrical company and altered by a theatrical designer. A few professionals with industry experience worked pro bono, while team members tried their hands at various filmmaking capacities. Ells and Hi produced, wrote, designed, cast, and edited the film. In addition, Ells sketched the storyboards and designed the sets, which she also painted, while Hi worked with the carpenters. She drew on her theatrical background for the design of the Caligari-inspired decors of canvas and wood, made in the style of stage flats and drops. On set, Ells directed the actors in the manner of silent film directors, coaching their performances verbally while the camera was running. Hi worked as cinematographer and camera operator.

The production of Der Glöckner explored the ensemble methodology of the Expressionist production model. On one hand, encouraging input on set about disparate ideas could syphon untapped layers of meaning with regard to design and style, cinematic vision, and communal creative engagement and ownership, thus bolstering the filmmaking experience and benefitting the project. On the other hand, however, full and active participation in the process of all voices threatens to slow shooting to a crawl, which, due to the tight budget and timeframe, can invariably raise tensions on set, and eventually negatively affect

3 From 1901-1934, theatre producer and director Max Reinhardt operated a total of thirty German theatres, designing extravagant revolving stages, intricate lighting plots, and unusual staging techniques. His influence on lighting and staging of crowd scenes for early German cinema can be seen in many films including those of G. W. Pabst, Fritz Lang, and later on American director Otto Preminger.

4 The funding was a mixture of personal contributions and government grants. Similarly, the Weimar government also supported its film industry financially, since it was among the few viable national exports at the time (Burns 2013, 78).

5 This figure includes the equivalent cash value of all deferred and donated labour and resources. 
the quality of the project. Ells and Hi navigated this very fine line, inviting creative crew participation as a method of encouraging commitment, stopping short of the inevitable ensuing confusion and endless discussion by ensuring the creative process was ultimately coordinated by director Ells, who channelled all efforts and ideas towards a unified vision and cohesive style, constructed on the creative and thematic scaffolding that was developed before shooting began. As Caligari demonstrated, even if all creative departments (sets, costumes, lighting design, etc.) were given creative autonomy during the pre-production period, once shooting began, it was Wiene who unequivocally took charge of bringing together all aspects into one coherent whole (Burns 2013, 116-117).

Der Glöckner takes place in what could be defined as a typical Expressionist milieu - a Central European mountain village circa 1914 (and thus reminiscent of the place and time of Caligari), [Fig. 1] and reveals the depressingly claustrophobic world of the protagonist, who is a bell-ringer at the local church. The flatness of the sets, painted in abstract broad strokes, conveys his twodimensional existence, daily drudgery and isolation. Watching the village life from on high, the Bell-ringer comes through as the archetypal everyman of Expressionism, the eponymous central character of From Morning to Midnight (Von morgens bis mitternachts, 1920), Karl Heinz Martin's adaptation of Georg Kaiser's play.

A self-conscious pastiche of German Expressionism, Der Glöckner pays homage to the elaborate designs of this unduly neglected classic by construing in a similar manner the flimsy flat walls of the Bell-ringer's village. Indeed, Der Glöckner represents a compendium, so to speak, of intertextual references to both well-known and almost forgotten Expressionist works. There are, for example, the unmistaken references to Caligari with regard to the in-camera iris scene transitions, and the miniature, two-dimensional town sets. Then there is the backlight silhouette effect, enveloping Belle in her dancing dream sequence. [Fig. 2.] Combined with other optical effects, the silhouette effect brings forth the uncanny nature of the Bell-ringer's beloved in a way Lang portrays the demonic spirit that seizes the False Maria in Metropolis. There is also the episode of a soldier, leaving his bride behind as he heads to the front, influenced by Asphalt (Germany: UFA, 1929), a little-known film by Joe May. Moreover, the portrayal of soldiers in trenches comes straight from Homecoming (Heimkehr, 1928), another late Expressionist film of May's. The ominous invading army, on the other hand, is depicted metonymically by soldiers' shadows, cast on the village walls [Fig. 3] - a formal device, inspired by Warning Shadows. 
The garish sets of Der Glöckner are neither a shocking end in themselves, nor is the clownish makeup of the Bell-ringer meant as a sole homage to Emil Jannings's down-trodden doorman from The Last Laugh. As is typical of postmodern cinematic authorship, there is nothing accidental in the self-reflexive artifice of Der Glöckner, where all hybrid elements work together in fostering a complex and simultaneous interplay between ironic alienation from characters, and warm empathy for them.

Moreover, in their preparatory work, Ells and Hi did not only study the cinematic conventions of German Expressionism, but also familiarized themselves with the critical and psychological discourses of the time. Thus in light of Expressionist symbolism, which is closely related to its contemporaneous interest in psychoanalysis and analytical psychology, the bell-tower could be interpreted as a stand-in for the Bell-ringer's persona; the bell itself for his psyche; and his young beloved Belle for his estranged soul or anima ${ }^{6}$ The tower also appears on the 19th Tarot trump card, called The Falling Tower. As Sallie Nichols explains: "for, whoever lives exclusively high above the earth loses contact with it, with his fellow men, and inevitably with the instinctual, earthy aspect of himself. He becomes isolated. The panoramic view, statistical and intellectual, tends to obliterate the warm personal contacts of everyday life" $(1980,288)$.

The film opens with a shot of Belle, seen from the Bell-ringer's subjective point of view. It reveals an unusual-looking young girl who shows up inconspicuously on the edge of the crowd whenever the bell is rung. Throughout the film, the girl gets closer and closer to the Bell-ringer, and when finally the bell rope breaks, she appears before him in the bell-room, wounded. As the bell is tolled for a funeral, Belle appears in mourning clothes. Finally, she haunts the Bell-ringer's dream, dancing in a bell-shaped dress as a perfect anima projection, seeking union with his psyche.

In the final sequence, as the town gets destroyed by enemy shelling, the top of the bell-tower is blown off, and the bell tumbles to the square below, irreparably cracked. The Bell-ringer emerges from the church rubble, and picks up Belle, lying mortally wounded next to the broken bell. She strokes his face and expires in his arms. Devastated, he spends the night grieving by the broken bell until Belle's semi-transparent ghost rises from the rubble, embraces the hunched Bell-ringer, and fades into him, visualizing what Jung called reintegration of the psyche. The

6 According Carl Gustav Jung, "the feelings of a man are so to speak a woman's, and appear as such in dreams. I designate this figure by the term anima, because she is the personification of the inferior functions which relate a man to the collective unconscious" $(1968,99)$. 
destruction of the bell-tower directly evokes the archetypal symbolism of the falling of the Tarot Tower, and the opportunities it yields for liberation and integration, prompting the return of Belle, the anima that had been projected onto the world.

At dawn, the Bell-ringer walks away from the destroyed town and the broken bell, which stands for his former divided self. Transformed and integrated, he turns toward the rising sun, and confidently steps into the three-dimensional world, leaving all vestiges of his former two dimensional self behind. This final vast prairie shot is the only one taken outside the studio, [Fig. 4] thus emphasizing the disparity between the abstract two-dimensional sets and the natural world, between the lifeless realm behind and the vibrant terrene ahead, and between the Bell-ringer's old and new self. The symbolism of this scene alludes to what Jung calls the transcendent function: the result of a meshing or dialogue between the conscious and the unconscious mind (in this case personified by the anima), which leads to individuation or psychic wholeness. ${ }^{7}$

In leaving the old world behind, the Bell-ringer becomes a modern man, described by Jung as one who has become "unhistorical," for he "has estranged himself from the mass of men who live entirely within the bounds of tradition. Indeed, he is completely modern only when he has come to the very edge of the world, leaving behind him all that has been discarded and outgrown, and acknowledging that he stands before a void out of which all things may grow" (Jung 1968, 197).

In addition to Jung, Der Glöckner references other contemporaneous intellectual obsessions, most notably the need to re-evaluate the Romantic view of progress. Thus while before WWI, the superiority of human reason - in tune with Enlightenment ideas - had been lauded as a positive aspect of the natural order, the war's destructive end prompted a radical turn towards the natural world for healing and relief. The naïve faith in technology and progress was swiftly swept away by unconditional trust in the spontaneity of nature as the sole remedy for rationalist artifice. This sentiment is illustrated by the final shot of the film, where the Bell-ringer confidently paces away from the overwrought artificial sets, and into the unknown void of the natural, three-dimensional world. And although in most German Expressionist films nature was reconstructed in studio, with its final shot Der Glöckner comes closest to Murnau's Nosferatu and Lang's Die Niebelungen, the two most prominent films from the era to boldly mix

7 "The tendencies of the conscious and the unconscious are the two factors that together make up the transcendent function. It is called 'transcendent' because it makes the transition from one attitude to another organically possible” (Jung 2015, 3029, para. 145). 
two-dimensional Expressionist set designs with location shots. The indexical nature of the cinematic image has always attracted the attention of film theorists, and it is enough to mention the preoccupations of the early German theorist Siegfried Kracauer with the "redemption of the physical reality" in fiction film (1960). ${ }^{8}$ Additionally, specific interests of André Bazin, the intellectual architect of French New Wave cinema, relate to the sudden encounters with realness - or with the auratic aspect of the pro-filmic reality - as a particular moment in the cinematic text, which "ruptures or short-circuits representation producing an effect of pure temporal distance, of materiality and its loss" (Galt 2006, 73). Bazin calls this phenomenon "aesthetic catalyst" when describing the effect of the "concrete forest" alongside the contrived artificial settings in Die Niebelungen. In his view, no amount of artistry could match "the trembling of just one branch in the wind, and the sunlight [...] enough to conjure up all the forests in the world" (Bazin 1967, 111).

Therefore taking the production out of the studio environment and under the open sky represents yet another key moment in Ells's and Hi's faithfulness to German Expressionist aesthetics. The metaphysical importance of this paradigmatic shift cannot be overestimated as it signals a decisive move out of the confines of the early cinema aesthetics. As Christina Stojanova writes, "catalyzed by the turmoil of the Great War and refined in its aftermath, the swiftly evolving international language of cinema [...] has challenged, deconstructed and even subverted all pre-existing aesthetics and cinematic approaches, clearing the way to its current capacity of a quintessential audio-visual metalanguage [...] particularly important in one of the most urgent philosophical and cultural debates of our time, that of technological progress and its consequences” $(2017,150)$.

\section{The Testament of Frankenstitch and Eyes of Sorrow Moon}

In his two experimental shorts, made for the Caligari Project, Gerald Saul remains equally close to the aesthetic and conceptual legacy of German Expressionism as a way of exploring new venues for independent cinema. Saul was particularly inspired by the pragmatism, inventiveness, and excess, demonstrated in Metropolis and Murnau's Faust (Faust: Eine deutsche Volkssage, 1926). He took particular interest in their use of miniatures, double exposure, and forced perspective, as

$8 \quad$ Kracauer is also the author of From Caligari to Hitler: A Psychological History of German Film (1947), one of the foundational texts on German Expressionism. 
well as in the complicated mechanical stages of Dr. Mabuse. Building on these, Saul applied contemporary digital tools alongside historical techniques. While both works explore visual Expressionist tropes, Eyes of Sorrow Moon is more narrative-based than the conceptually-based Frankenstitch. ${ }^{9}$

A combination of animation and puppetry, The Testament of Frankenstitch [Fig. 5] was shot on artificial sets, incorporating practical effects like projections, mirrors, strings, and magnets. Digital effects such as image compositing, graphic enhancements, and symbolically tinted colours were added in post-production. Along with a number of devices and themes, drawn from German Expressionist film, Saul was mostly inspired by fairy tales as the basis of early horror cinema. The story of Frankenstitch contains madness and delusion; natural versus artificial worlds; twinning and doubling; suicide, sacrifice, transformation; tricksters, ambiguity, pantomime, fantasy and magic as well as mad scientists and artificially created life; anguish and despair; lies and betrayal. Though the events of the story incorporate aspects of the hero's journey, they are structured through a more mathematical pattern.

Frankenstitch is a monster, made out of cloth by Edison, a fictionalized version of the great American inventor. The artificial creature is meant to become a vessel of Edison's intelligence, thus ensuring his immortality as a gambit in Edison's ongoing battle with Tesla, a fictionalized version of another great inventor the Serbian Nicolai Tesla. Inspired by the original script of Metropolis, their characters, rivalry, and the construction of artificial intelligence have however little in common with the real-life dispute of Edison and Tesla over the use of AC current. The complicated story of the tragic love affair between Fredersen, Rotwang, and Hel in Metropolis - lost for a long time but recently rediscovered is now part of the restored latest version of the film. In its full version, however, this story - like the one of Frankenstitch - is difficult to grasp in a single viewing. In Saul's film, the monster is lured into Tesla's lab, located at the centre of the moon, where he finds himself in a mirror chamber, strongly remindful of Lang's Dr. Mabuse and Woman in the Moon (1929). Moreover, while in the lab, Frankenstitch finds Tesla's creation, the Bride, and falls in love with her. [Fig. 6.]

The fight of Tesla and Edison in the mirror chamber generates multiple reproductions of themselves, alluding to the popular Expressionist doubling trope. It is enough to mention the True and the False Maria in Metropolis, and surely The Student of Prague (Der Student von Prag, Henrik Galeen, 1926), where

9 The title refers both to "Frankenstein" as well as to "Stitchpunk," a subgenre of Steampunk, which takes place in a world inhabited by macabre crudely sewn cloth-based toys or puppets. 
the mirror image of the eponymous Student turns into his evil doppelganger. [Fig. 7.] When the glass cracks, the moon explodes, and all Frankenstitch characters fall to earth, thus replicating the traditional fatalistic connotation of a broken mirror as a symbolic disruption of one's identity, yet another well-known Expressionist narrative trope.

Frankenstitch brings together an array of complex character interactions, allowing only for a very brief exposition of each new development. Each character in this experimental mathematical-based storytelling structure is introduced in a sequence of one-on-one conversations with another character. As Frankenstitich runs only six minutes, this rigorous structure places serious demands on the ability of the viewers to familiarize themselves with the personages, to place them within the plot, and to contextualize their complicated relations. In order to make the story visually intriguing, live action faces were superimposed onto miniature figures, and then animated on backgrounds in constant motion, thus making the experience deliberately overwhelming. ${ }^{10}$ Telling the story this way points to Saul's intention to explore and distil a distinctly non-Hollywood structure, stemming from the classical Expressionist films, yet closer to contemporary Expressionist cinematic renditions like Guy Maddin's shorts Heart of the World (2000) and Odilon Redon or The Eye Like a Strange Balloon Mounts Toward Infinity (1995).

Saul's second short, Eyes of Sorrow Moon [Fig. 8] tells a story of a family coming to a town where strangers are not welcome, and thus puts the distrust of the strange other at its core. Fearing their boy would be ostracized for his appearance and uncanny psychic ability, the family tucks him in the attic. The child's growing anguish and desperation, caused by the social repression he is subjected to, constitute yet another common motif of German Expressionism, explaining the self-loathing of characters like the pianist in Robert Wiene's The Hands of Orlac (Orlacs Hände, 1924). All the more that - as Expressionist films show us - psychological distress leads to unwise and ultimately self-destructive choices as those of the murderous Martin Fellman in G. W. Pabst's Secrets of a Soul (Geheimnisse einer Seele, 1926).

The only spoken words in Eyes of Sorrow Moon are in the opening scene, when the mother's voice is heard telling her boy in the attic the story about his three older brothers. Illustrated by an animated inset, the story follows a fairy-tale structure, describing how the first two sons fail, but the third, the fool, succeeds (von Franz 1995, 221-222). The events of Sorrow Moon proceed in a Scheherazade-like way of a story within a story but transcend the archetypal narrative to reveal what

10 In 2017 this film was awarded a "Worst Screenplay" award at the Whoops Film Festival in NYC. 
happens to the ostracized fourth son. His only companions in the attic are a rat, a spider, and a moth, who offer him food and friendship. The spider - taking his cue from an illustrated book - attempts to kidnap the Mayor's daughter and bring her to the attic to keep the boy's company. Predictably, the girl dies, and the townsfolk set the boy's house on fire. Through a magical transformation, visually similar to the one of the robot turning into the False Maria (Metropolis), and the assassin, remoulding his face (Woman in the Moon), the boy grows wings and escapes to the moon, wherefrom he fetches water to quench the fire. Freed from the prison of his parents' fears, he sets off on his own journey.

Both Frankenstitch and Eyes of Sorrow Moon were realized on micro budgets. In Sorrow Moon, the shortage of financing was compensated by a carefully planned pre-production process. The props and costumes were made by the director, while the studio shoot with actors was restricted to one day. The small crew consisted of young professionals who knew each other, were able to execute various filmmaking tasks, and were above all inspired by their common passion for Expressionist film aesthetics. ${ }^{11}$ Moreover, as an editor of both films, Saul was able to additionally save time by shooting only scenes he considered essential, foregoing the level of coverage and number of takes considered standard by larger productions. The two actors performed on minimal sets, interacting with puppets operated off-screen by strings and wooden rods. Based on fairy tale tropes, the film world is immersed in lighting effects, swirling portentous sky, and fog reminiscent of Murnau's Faust - animated live on set by using a rear projector thus creating a veritable Stimmung effect.

Costs were further minimized during post-production by combining live action scenes with animated insets in post-production, and by replacing period Expressionist techniques with current technology. For Saul it was better to remain true to the spirit of the movement, instead of pursuing meticulously the letter of early technological effects available to German Expressionists in the 1920s.

Eyes of Sorrow Moon is a highly stylized short film, where Expressionist aesthetics are as important in conveying the story as are subtitles. While the dangers of the world are implied through darkness, shadow, and swirling skies, the unnatural movement of the protagonist reinforces additionally the uncanny atmosphere. The tortured pantomime of the lead actor is enhanced by his make-

11 As part of the same student cohort at the Film Department (University of Regina), the cinematographer and the two crew members made an excellent team thanks to their flexibility on the set. As a matter of fact, staffing crews with members from film-school cohorts is a widely known successful strategy for young filmmakers, but rarely sustainable outside independent film projects. 
up, large and emotive eyes, painted on top of his eyelids. [Fig. 9.] Performing blind, the actor had to rely on the silent film directing methodology - that is, on the director's continuous verbal instructions while the camera was rolling. Using words like strings, manipulating every gesture of the performer, was a hallmark of Expressionist acting, which boldly sacrificed naturalism for emotive movement as Caligari, Nosferatu, and Hands of Orlac eloquently demonstrate. This style of acting was the only way of bringing together bizarre stories with stylized locations, creating the unique sense of cinematic unity German Expressionism has been appreciated for nearly a century now.

Sorrow Moon, unlike Frankenstich, follows a linear story, which - as in Der Glöckner - ensures an easier rapport with the audience, without sacrificing its radical aesthetic or production model. As independent filmmakers, Ells and Saul have often experienced in the past restrictions of low budgets, small production crews, and distribution difficulties. While enjoying more creative freedom than commercial filmmakers, as a rule they have less access to audiences. North American independent milieu is indeed a small flame when compared to Hollywood inferno. But what if there were a way out of competition with Hollywood, a way of standing alone? The Caligari Project experience has confirmed what their German colleagues discovered back in the 1920s and proved that it was indeed possible for filmmakers from smaller film centres to stand their ground - individually as well as collectively - and produce sustainable works, if they were brave enough to circumvent the rules and expectations established by commercial cinema.

Every great dream begins with a dreamer. It has been nearly a hundred years since viewers first saw the mysterious cabinet of Dr. Caligari open on the screen. Indeed, students of film history may be tempted to see the legacy of German Expressionism only in the stylized confection of surreal shadows, dense symbolism and psychological confusion. Yet - as the filmmakers of the Caligari Project have discovered - a complex and devoted research into the aesthetic and production practices of this cinematic movement could uncover a wealth of experience. For, along with building the foundations of contemporary cinematic language, German Expressionism passed down to us a unique production model for creative innovation through inspired collaboration. 


\section{References}

Alton, John. 1949. Painting with Light. New York: Macmillan.

Bach, Steven. 1999. Final Cut: Art, Money, and Ego in the Making of Heaven's Gate, the Film that Sank United Artists. New York: Newmarket Press.

Bazin, André. 1967. What is Cinema? Berkeley: University of California Press.

Bergstrom, Janet. 2014. Warning Shadows: German Expressionism and American Film Noir. In Film Noir: Classical Traditions, eds. H. Pettey, S. White, R. B. Palmer, 38-57. Edinburgh: Edinburgh University Press.

Brockmann, Stephen 2010. A Critical History of German Film. Rochester, New York: Camden House.

Burns, William. 2013. Emptying the Cabinet: An Exploration of the Origins, Impact and Legacy of the Expressionist Film Movement of Post-World War I Germany. New Jersey: Drew University dissertation.

Eisner, Lotte. 1980. The German Silent Film (foreword). In Great Film Stills of the German Silent Era: 125 Stills from the Stiftung Deutsche Kinemathek, ed. John Kobal, iv-vi. New York: Dover Publications.

Elsaesser, Thomas. 2016. Expressionist Cinema - style and design in film history. In Expressionism in the Cinema, eds. O. Brill and G. D. Rhodes, 15-40. Edinburgh: Edinburgh University Press.

Galt, Rosalind. 2006. Redrawing the Map: The New European Cinema. New York: Columbia University Press.

Hardt, Ursula. 1996. From Caligari to California: Erich Pommer's Life in the International Film Wars. Oxford: Berghahn.

Hirsch, Foster. 1981. The Dark Side of the Screen: Film Noir. New York: Da Capo Press.

Jaglom, Henry. 1992. The Independent Filmmaker. In The Movie Business Book, ed. J. E. Squire, 74-82. New York: Simon \& Schuster.

Jung, C. G. 1968. Analytical Psychology - Its Theory and Practice. New York: Random House.

Jung, C. G. 2015. Collected Works of C.G. Jung: The First Complete English Edition of the Works of C.G. Jung. New York: Routledge.

Kracauer, Siegfried. 1960. Theory of Film: The Redemption of the Physical Reality. Princeton University Press.

Marie, Michel. 2003. The French New Wave: an Artistic School. Malden, MA: Blackwell. 
Nichols, Sally. 1980. Jung and the Tarot. New York: Samuel Weiser, Inc.

Reimann, Walter. 2016 [1925]. An Afterword to Caligari. In The Promise of Cinema, German Film Theory 1907-1933, eds. A. Kaes, N. Baer, and M. Cowan, 438-440. Oakland: University of California Press.

Stojanova, Christina. 2017. The Great War: Cinema, Propaganda, and the Emancipation of Film Language. Acta Universitatis Sapientiae, Film and Media Studies vol. 14: 131-156.

Tsivian, Yuri. 2004. New Notes on Russian Film Culture between 1908 and 1919. In The Silent Cinema Reader, eds. Lee Grieveson and Peter Krämer, 339-348. London: Routledge.

von Franz, Marie-Louise. 1995 [1974]. Shadow and Evil in Fairy Tales. Boulder, Colorado: Shambhala Press.

Wiene, Robert. 2016 [1922]. Expressionism in Film. In The Promise of Cinema,

German Film Theory 1907-1933, eds. A. Kaes, N. Baer, and M. Cowan, 436437. Oakland: University of California Press.

\section{List of Figures}

Figure 1. The flat miniature town shot through a cardboard iris in Der Glöckner (2016). (Copyright C. Ells \& B. Hi.) Figure 2. Belle dances in silhouette in the Bellringer's dream in Der Glöckner (2016). (Copyright C. Ells \& B. Hi.)
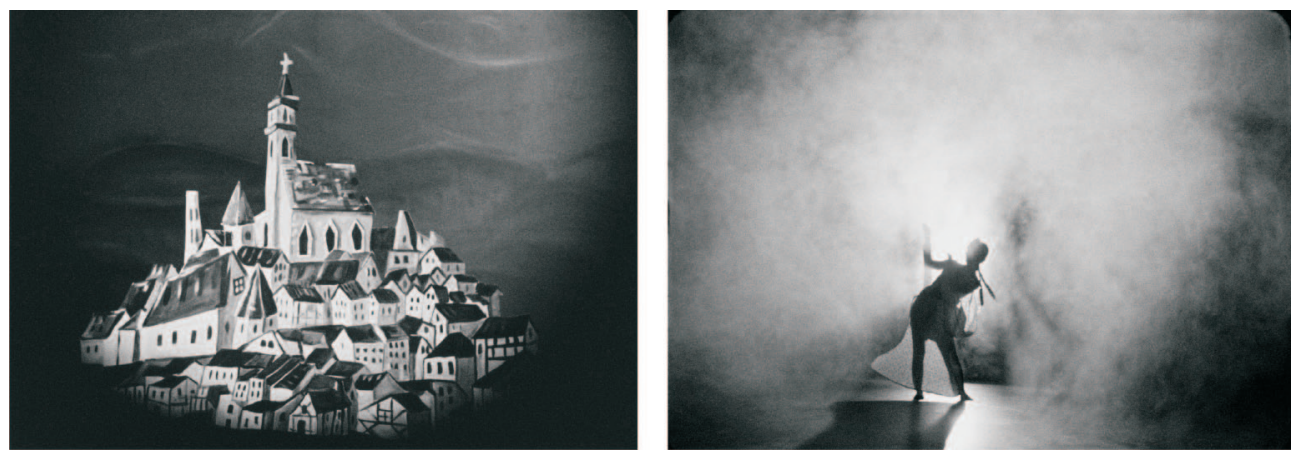
Figure 3. Shadows of invading soldiers on village walls in Der Glöckner (2016). (Copyright C. Ells \& B. Hi.) Figure 4. The Bell-ringer leaves his previous twodimensional existence and strides into his three-dimensional future in Der Glöckner (2016). (Copyright C. Ells \& B. Hi.)
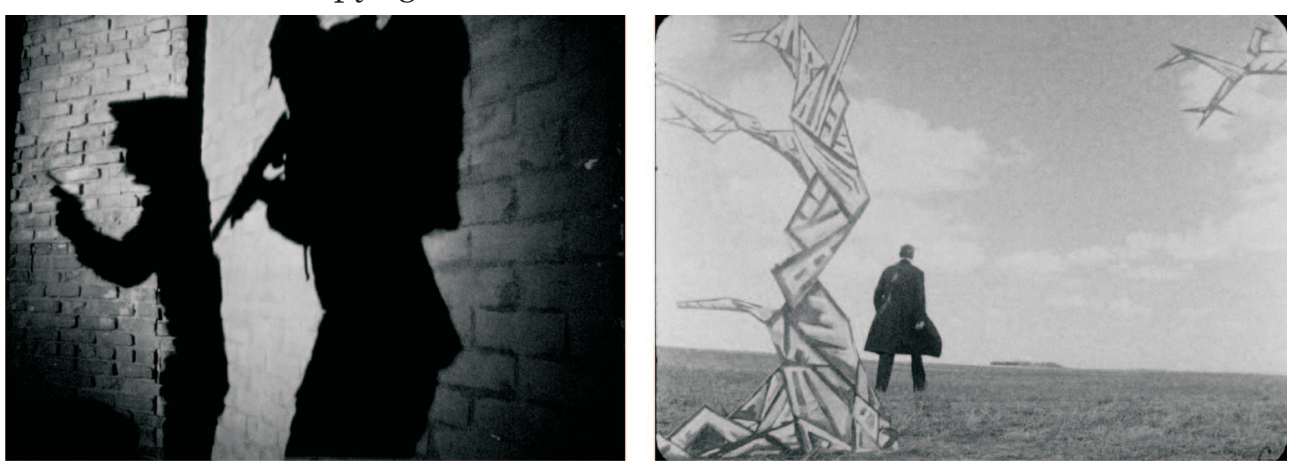

Figure 5. Nicolai Tesla, with face and voice of Erik Sirke, tempts the colourized figure of the Frankenstitch monster, with superimposed face and voice of William Bessai-Saul, in The Testament of Frankenstitch (2016). (Copyright G. Saul.)

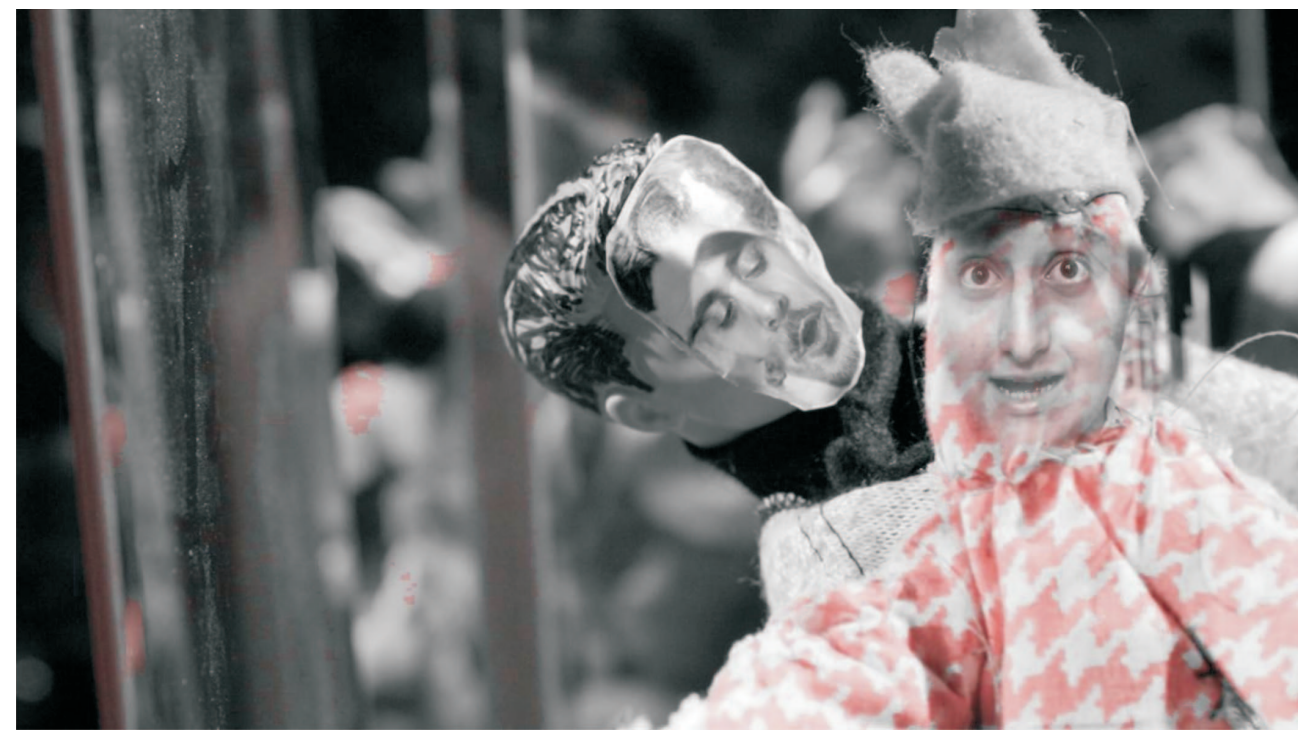


Figure 6. The macabre Bride in The Testament of Frankenstitch (2016). (Copyright G. Saul.)

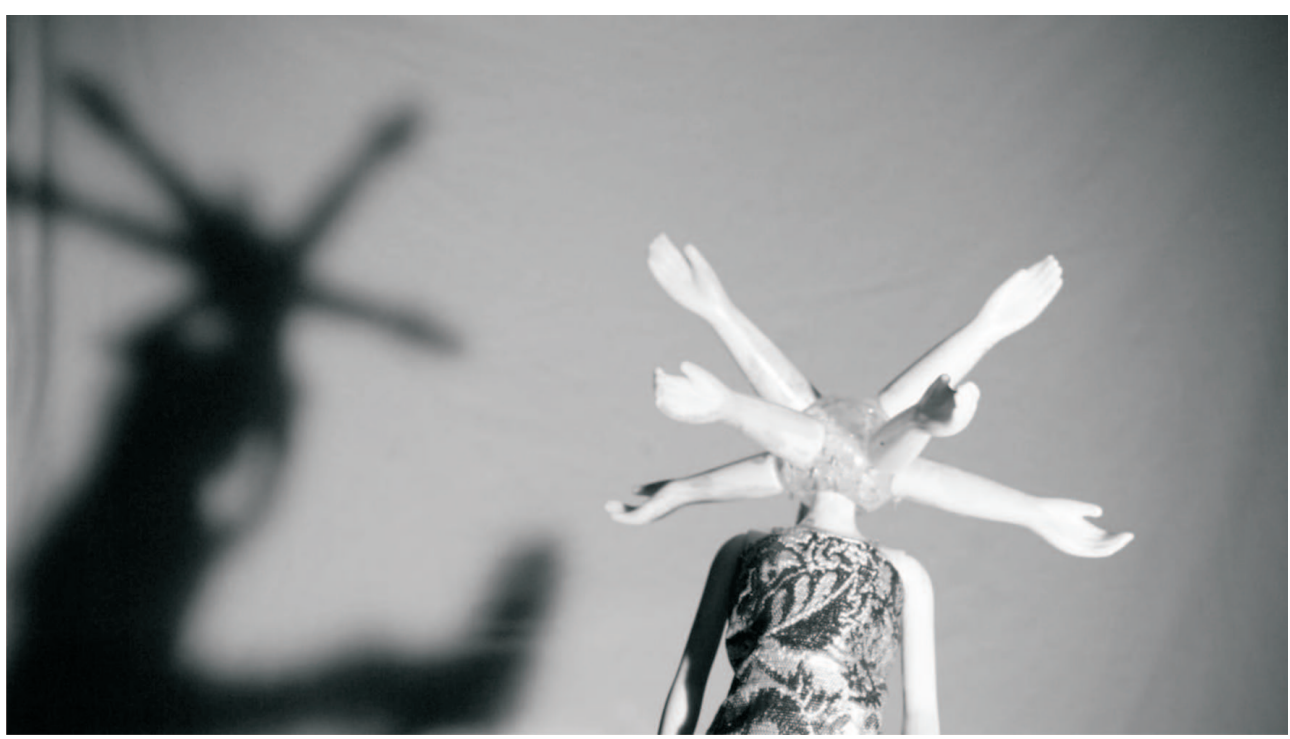

Figure 7. Digitally tinted image of Tesla and Edison summon doppelganger minions in the moon base hall of mirrors in The Testament of Frankenstitch (2016). (Copyright G. Saul.)

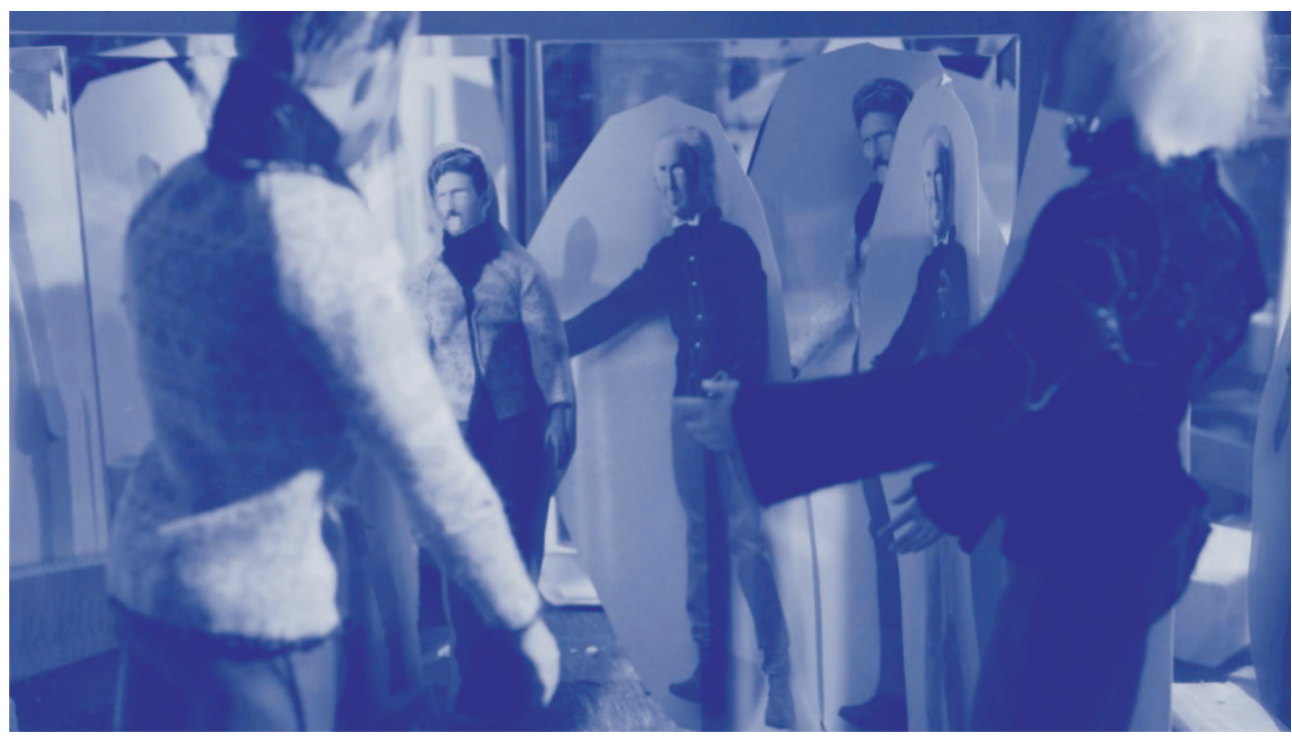


Figure 8. The dead girl, played by Alice Willett, dances as a puppet to the will of the spiders in Eyes of Sorrow Moon (2016). Figure 9. William Bessai-Saul with eyes painted on his eyelids as the boy in Eyes of Sorrow Moon (2016). (Copyright producer/director Gerald Saul with cinematographer Erik Sirke.)
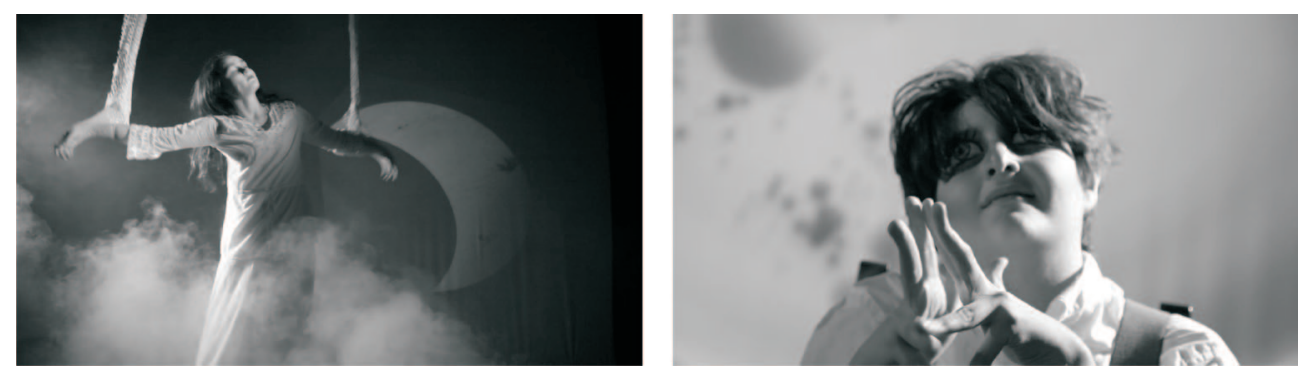